\title{
HASIL ANALISIS KEBUTUHAN PEMANFAATAN LABORATORIUM FISIKA SEBAGAI PENUNJANG HASIL BELAJAR SISWA
}

\author{
Cintia Pinatih Sari ${ }^{\text {a) }}$, Liszulfah Roza ${ }^{\text {b) }}$ \\ Program Studi Pendidikan Fisika, Fakultas Keguruan dan Ilmu Pendidikan, Universitas Muhammadiyah Prof. \\ DR. HAMKA Jl. Tanah Merdeka No. 20, Jakarta Timur 13830, Indonesia \\ Email: a)cintiapinatih@gmail.com, b)liszulfahroza@gmail.com
}

\begin{abstract}
Abstrak
Laboratorium merupakan suatu ruang atau tempat berupa gedung untuk belajar, percobaan dan penyelidikan dimana siswa dapat berinteraksi dengan berbagai alat dan bahan guna meningkatkan mutu serta sistem pengajaran. Di dalam jurnal ini membahas studi pendahuluan berupa hasil analisis kebutuhan terhadap pemanfaatan laboratorium fisika sebagai penunjang hasil belajar siswa. Tempat penelitian dilakukan di beberapa SMA yang terletak di Jakarta Timur dengan responden siswa-siswi kelas XI. Penelitian ini menggunakan metode kualitatif. Tahapan pengumpulan data yaitu melakukan survey dengan memberikan lembar kuesioner ke siswa-siswa, wawancara guru bidang studi dan kemudian dokumentasi. Teknik analisis data yang digunakan yaitu teknik deskriptif kualitatif, kemudian menarik kesimpulan dari hasil yang telah di dapatkan.
\end{abstract}

Kata-kata kunci : Pemanfaatan, Laboratorium Fisika, Hasil Belajar Siswa

\begin{abstract}
Laboratories are a space or place of building for study, experiments, and investigations to interact with various tools and materials to improve the quality and teaching system. This journal discusses preliminary studies in the form of an analysis of the need to use physics laboratory to support students' learning outcomes. The research venue was conducted at several high schools located in East Jakarta with class XI students. This research uses qualitative methods. The data collection stage is surveying by providing a questionnaire to students, interviews teachers' field of study, and documentation. The data analysis technique used is a qualitative descriptive technique, then conclude from the results that have been in the get.
\end{abstract}

Keywords : Utilization, Physics laboratory, Student learning outcomes

\section{PENDAHULUAN}

Pendidikan adalah salah satu hal terpenting untuk seluruh Warga Negara Indonesia (WNI), tanpa pendidikan kita sebagai manusia khususnya warga Indonesia tidak akan mengalami banyak perkembangan yang signifikan. Dengan pendidikan, maka kita akan memiliki banyak kelebihan diantaranya dengan beragam ilmu yang ada di dunia pendidikan. Dalam Undang-Undang Nomor 20 
Tahun 2003 tentang Sistem Pendidikan Nasional, bab II pasal 3 dijelaskan tujuan diselenggarakan pendidikan yaitu : "Pendidikan nasional berfungsi mengembangkan kemampuan dan membentuk watak serta peradaban bangsa yang bermartabat dalam rangka mencerdaskan kehidupan bangsa, bertujuan untuk berkembangnya potensi peserta didik agar menjadi manusia yang beriman dan bertakwa kepada Tuhan Yang Maha Esa, berakhlak mulia, sehat, berilmu, cakap, kreatif, mandiri, dan menjadi warga negara yang demokratis serta bertanggung jawab".

Pendidikan yang baik harus mampu memfasilitasi orang-orang yang menempuh dunia pendidikan secara maksimal sehingga dapat berkontribusi dengan baik untuk perkembangan dunia pendidikan. Salah satu komponen pendidikan yang dapat memenuhi itu adalah sarana dan prasarana. Sarana pendidikan mencakup semua yang bisa dikenakan sebagai alat dalam mencapai maksud atau tujuan pendidikan. Sedangkan prasarana adalah semua sesuatu yang merupakan penunjang utama terselenggaranya suatu proses pendidikan. Salah satu sarana dan prasarana yang tersedia untuk menunjang proses pembelajaran di sekolah yaitu laboratorium.

Dalam pembelajaran sains, laboratorium berperan sebagai tempat untuk menunjang kegiatan belajar di kelas. Salah satu mata pelajaran sains yang membutuhkan laboratorium adalah mata pelajaran fisika. Laboratorium tidak hanya berperan sebagai penunjang kegiatan belajar, tetapi upaya untuk meningkatkan kualitas kegiatan belajar mengajar sehingga peserta didik tidak hanya mendapatkan teori-teori di dalam kelas tetapi mereka juga dapat membuktikan teori-teori tersebut dengan melakukan percobaan atau yang biasa disebut praktikum. Melalui kegiatan praktikum, peserta didik dapat lebih memahami konsepan dari teori yang sudah didapat [1].

Laboratorium adalah tempat belajar mengajar melalui metode praktikum yang dapat menghasilkan pengalaman belajar dimana siswa berinteraksi dengan berbagai alat dan bahan untuk mengobservasi gejala-gejala yang dapat diamati secara langsung dan membuktikan sendiri sesuatu yang dipelajari jadi suatu laboratorium sekolah mempunyai peranan yang sangat penting dalam upaya meningkatkan mutu serta sistem pengajaran [2].

Dalam beberapa sekolah ditemui bahwa keberadaan laboratorium fisika di sekolah terkadang tidak digunakan dengan baik atau sebagaimana fungsinya untuk tempat praktikum sebagai penunjang belajar peserta didik. Peserta didik bisa mendapatkan hasil belajar yang baik dengan ditunjang oleh sarana seperti laboratorium. Hasil belajar siswa adalah kemampuan yang diperoleh anak setelah melalui kegiatan belajar. Karena belajar itu sendiri merupakan suatu proses dari seseorang yang berusaha untuk memperoleh suatu bentuk perubahan perilaku yang relatif menetap [3].

Menyadari pentingnya laboratorium dalam menunjang kegiatan belajar di sekolah, diperlukan pengelolaan yang baik oleh guru ataupun laboran agar pemanfaatan laboratorium terlaksana secara efektif. Agar fungsi utama itu dapat berjalan dengan baik, maka laboratorium fisika sekolah sebaiknya memiliki fasilitas-fasilitas ruangan untuk kegiatan proses pembelajaran fisika, kegiatan administrasi, dan pengelolaan laboratorium [4].

\section{METODOLOGI PENELITIAN}

Metode penelitian yang digunakan adalah metode penelitian kualitatif. Penelitian kualitatif adalah pengumpulan data pada suatu latar alamiah dengan maksud menafsirkan fenomena yang terjadi dimana peneliti adalah sebagai instrument kunci, pengambilan sampel sumber data dilakukan secara purposive dan snowbaal, Teknik pengumpulan dengan triangulasi (gabungan), analisis data bersifat induktif/kualitatif, dan hasil penelitian kualitatif lebih menekankan makna dari pada generalisasi [5].

Penelitian ini dilakukan di tiga SMA di Jakarta Timur dengan sampel kelas XI IPA semester genap tahun ajaran 2019/2020. Penelitian ini dilaksanakan selama bulan Februari. Tahap pertama yang dilakukan adalah pengumpulan data yaitu melakukan survey dengan memberikan lembar kuesioner ke peserta didik, kemudian wawancara guru bidang studi dan yang terakhir yaitu dokumentasi. Teknik analisis data yang digunakan yaitu teknik deskriptif kualitatif, kemudian menarik kesimpulan dari hasil yang telah di dapatkan. 


\section{HASIL DAN PEMBAHASAN}

1. Berikut ini dijabarkan hasil analisis kebutuhan yang diperoleh dari peserta didik di tiga SMA yang terletak di Jakarta Timur. Pada GAMBAR 1 memuat pertanyaan "Apakah di sekolah terdapat laboratorium fisika?"

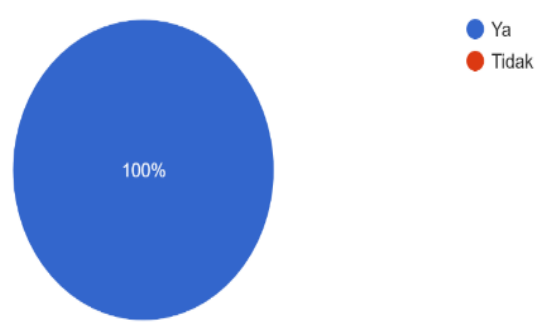

GAMBAR 1. Hasil analisis kebutuhan mengenai ketersediaan laboratorium fisika

Berdasarkan hasil pengumpulan data analisis kebutuhan, diperoleh jawaban sebanyak $100 \%$ bahwa di tiga SMA tersebut terdapat laboratorium fisika.

2. Berikut ini dijabarkan hasil analisis kebutuhan yang diperoleh dari peserta didik di tiga SMA yang terletak di Jakarta Timur. Pada GAMBAR 2 memuat pertanyaan "apakah laboratorium fisika yang tersedia di sekolah sudah digunakan untuk kegiatan praktikum?".

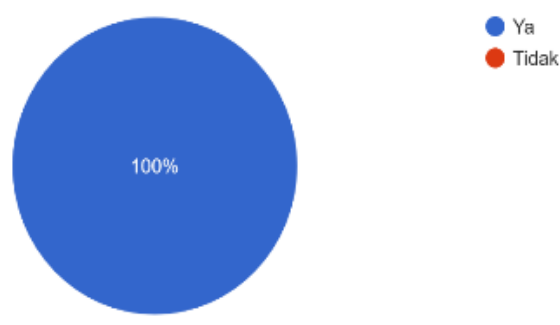

GAMBAR 2. Hasil analisis kebutuhan mengenai penggunaan laboratorium

Berdasarkan hasil pengumpulan data analisis kebutuhan diperoleh persentase $100 \%$ yaitu laboratorium fisika yang terdapat di sekolah sudah digunakan untuk kegiatan praktikum.

3. Berikut ini dijabarkan hasil analisis kebutuhan yang diperoleh dari peserta didik di tiga SMA yang terletak di Jakarta Timur. Pada GAMBAR 3 memuat pertanyaan mengenai "sudahkah dalam kegiatan praktikum dibentuk kelompok-kelompok?"

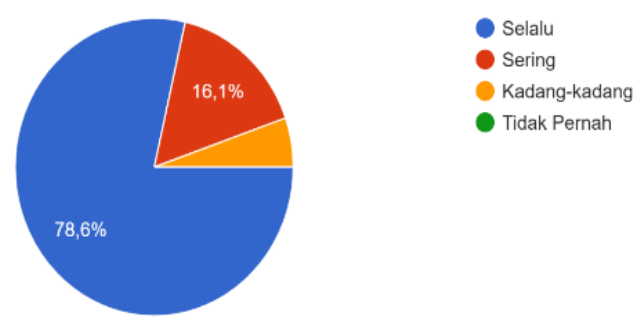

GAMBAR 3. Hasil analisis kebutuhan mengenai pembentukan kelompok dalam praktikum

Berdasarkan hasil pengumpulan data analisis kebutuhan, sebanyak 78,6\% kegiatan praktikum selalu dibentuk kelompok, lalu sebanyak 16,1\% menjawab sering. 
4. Berikut ini dijabarkan hasil analisis kebutuhan yang diperoleh dari peserta didik di tiga SMA yang terletak di Jakarta Timur. Pada GAMBAR 4 memuat pertanyaan "apakah peserta didik antusias dalam mengikuti praktikum fisika?"
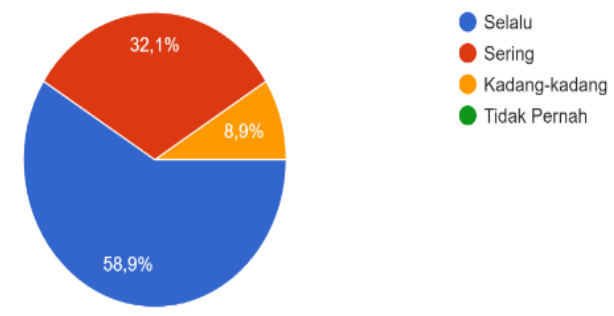

GAMBAR 4. Hasil analisis kebutuhan mengenai antusias peserta didik dalam mengikuti praktikum fisika

Berdasarkan hasil analisis kebutuhan, sebanyak 58,9\% peserta didik menjawab selalu antusias dalam mengikuti praktikum fisika, 32,1\% menjawab sering, dan 8,9\% peserta didik menjawab kadang-kadang.

5. Berikut ini dijabarkan hasil analisis kebutuhan yang diperoleh dari peserta didik di tiga SMA yang terletak di Jakarta Timur terkait "apakah peserta didik dibimbing oleh guru dalam melaksanakan praktikum fisika?".

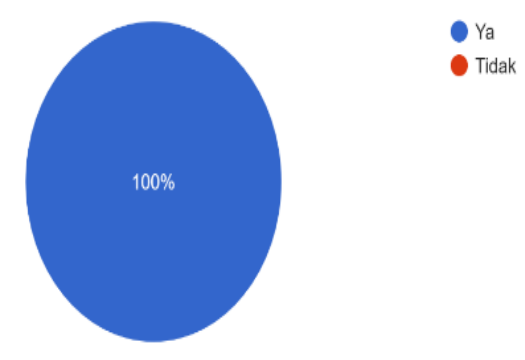

GAMBAR 5. Hasil analisis kebutuhan mengenai guru membimbing peserta didik dalam kegiatan praktikum

Pada GAMBAR 5 diperoleh hasil sebanyak 100\% peserta didik dibimbing oleh guru dalam melaksanakan praktikum fisika.

6. Berikut ini dijabarkan hasil analisis kebutuhan mengenai "apakah guru bidang studi menjelaskan tujuan dilaksanakannya praktikum fisika kepada peserta didik?".

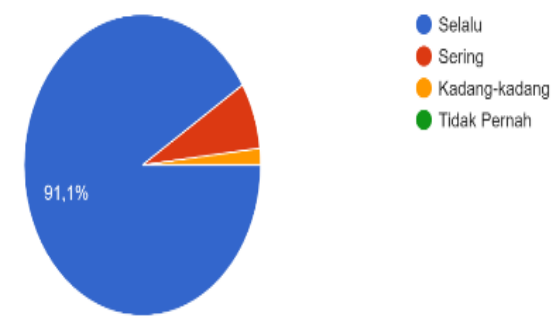

GAMBAR 6. Hasil analisis kebutuhan mengenai guru membimbing peserta didik dalam kegiatan praktikum

Berdasarkan hasil pengumpulan data analisis kebutuhan yang ditampilkan pada GAMBAR 6, sebanyak 91,1\% guru selalu menjelaskan tujuan dilaksanakannya praktikum fisika kepada peserta didik.

7. Berikut ini dijabarkan hasil analisis kebutuhan mengenai "apakah peralatan di dalam laboratorium fisika dapat digunakan untuk kegiatan praktikum?". 


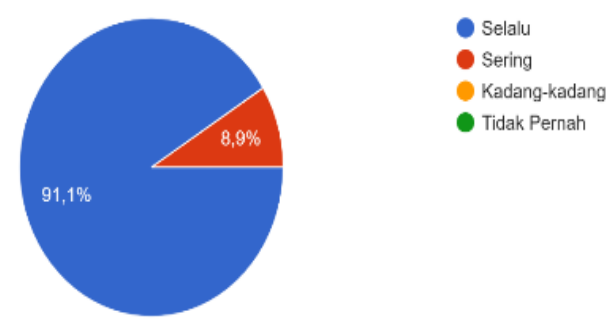

GAMBAR 7. Hasil analisis kebutuhan mengenai peralatan di dalam laboratorium

Pada GAMBAR 7, 91,1\% peserta didik menjawab peralatan di dalam laboratorium fisika selalu bisa digunakan untuk kegiatan praktikum, dan 8,9\% lainnya menjawab sering.

8. Berikut ini dijabarkan hasil analisis kebutuhan mengenai "apakah bahan-bahan untuk praktikum tersedia saat ingin melaksanakan praktikum fisika?".

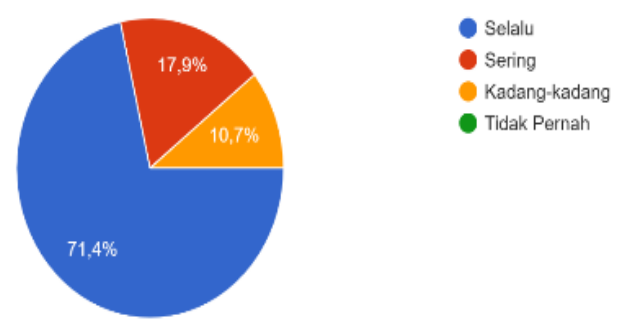

GAMBAR 8. Hasil analisis kebutuhan mengenai ketersediaan bahan-bahan untuk praktikum

Berdasarkan hasil pengumpulan data analisis kebutuhan, sebanyak $71,4 \%$ peserta didik menjawab selalu, $17,9 \%$ menjawab sering, dan $10,7 \%$ menjawab kadang-kadang terkait ketersediaan bahan-bahan untuk melaksanakan praktikum.

9. Berikut ini dijabarkan hasil analisis kebutuhan mengenai "setelah praktikum fisika, apakah diadakan diskusi oleh guru bidang studi?".

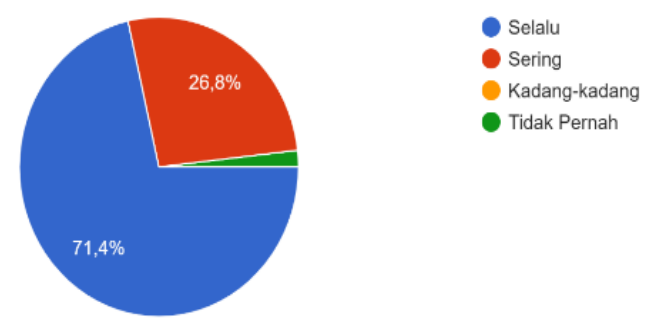

GAMBAR 9. Hasil analisis kebutuhan mengenai guru melakukan diskusi setelah melakukan praktikum

Berdasarkan hasil pengumpulan data analisis kebutuhan, diperoleh jawaban sebanyak 71,4\% selalu, dan 26,8\% guru sering mengadakan diskusi Bersama seelah dilaksanakannya praktikum fisika.

10. Berikut ini dijabarkan hasil analisis kebutuhan mengenai pertanyaan "apakah peserta didik merasa lebih memahami materi fisika setelah dilaksanakannya praktikum?". 


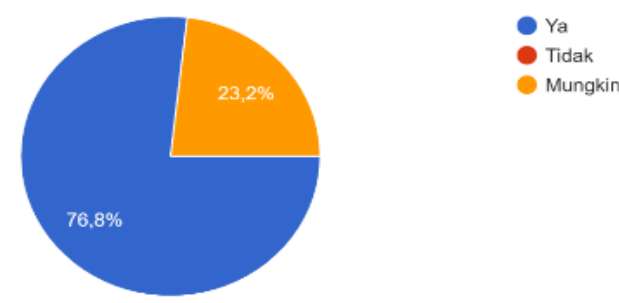

GAMBAR 10. Hasil analisis kebutuhan mengenai pemahaman materi fisika oleh peserta didik setelah dilaksanakan praktikum

Berdasarkan hasil pengumpulan data analisis kebutuhan, sebanyak $76,8 \%$ peserta didik menjawab lebih memahami materi fisika setelah melaksanakan praktikum dan 23,2\% peserta didik lainnya menjawab mungkin.

Berdasarkan kesepuluh simpulan yang didapat dari hasil analisis kebutuhan siswa dapat memahami materi fisika setelah diadakan praktikum. Tingkat pemahaman inilah yang nantinya akan mempengaruhi hasil belajar siswa. Selain tingkat pemahaman, miskonsepsi juga dapat memengaruhi hasil belajar siswa [6]. Miskonsepsi dapat diatasi dengan mengajar menggunakan eksperimen di lab virtual PhET [6]. Percobaan yang dilakukan selama praktikum juga membuat siswa mengalami peningkatan pada keterampilan penalaran ilmiah [7], proses sains [8] [9]. Keterampilan menalar ilmiah mengalami peningkatan karena selama eksperimen potensi mahasiswa dimaksimalkan melalui kesempatan yang luas kepada mahasiswa untuk bereksplorasi [7]. Keterampilan proses sains mengalami peningkatan berdasarkan hasil tes awal dan tes akhir yang menggunakan soal keterampilan proses sains tervalidasi [10].

\section{SIMPULAN}

Dari hasil analisis kebutuhan yang sudah diperoleh, dapat disimpulkan bahwa peserta didik juga membutuhkan kegiatan selain pembelajaran di kelas, salah satunya yaitu melaksanakan kegiatan praktikum di laboratorium. Dengan melaksanakan praktikum di laborarorium, peserta didik dapat menerapkan teori yang sudah didapatkan di kelas dan berlatih mengembangkan keterampilan. Dengan dilaksanakan praktikum di laboratorium, peserta didik lebih memahami materi fisika yang sudah diajarkan, dengan dibantu oleh guru bidang studi.

\section{UCAPAN TERIMAKASIH}

Terimakasih kepada seluruh pihak yang telah membantu dalam penyelesaian jurnal ini. Terimakasih juga kepada Ibu Dr. Liszulfah Roza, MIS. Selaku dosen yang telah membimbing dan membantu dalam pembuatan jurnal ilmiah, semoga dapat bermanfaat bagi penulis maupun pembaca.

\section{REFERENSI}

[1] Y. R. Liana, S. Linuwih, and S. Sulhadi, "The Development of Thermodynamics Law Experiment Media Based on IoT: Laboratory Activities Through Science Problem Solving for Gifted Young Scientists", JPPPF (Jurnal Penelitian dan Pengembangan Pendidikan Fisika), vol. 6, no. 1, pp. 51 - 64, 2020.

[2] W. Muliawan, “Teknik Laboratorium,” Yogyakarta: Deepublish, 2018.

[3] A. Susanto, "Teori Belajar dan Pembelajaran di Sekolah Dasar," Jakarta: Kencana Prenada Media Group, 2013.

[4] N. Sundoro Katili dkk, "Analisis Sarana dan Intensitas Penggunaan Laboratorium Fisika Serta Kontribusinya Terhadap Hasil Belajar Siswa SMA Negeri di Kabupaten Jembrana," eJournal Program Pascasarjana Universitas Pendidikan Ganesha, vol. 3, 2013. 
[5] A. Anggito and J. Setiawan, “Metodologi Penelitian Kualitatif," Sukabumi: CV Jejak, 2018.

[6] P. Sinulingga, T. J. Hartanto, and B. Santoso, "Implementasi Pembelajaran Fisika Berbantuan Media Simulasi PhET untuk Meningkatkan Hasil Belajar Siswa Pada Materi Listrik Dinamis", JPPPF (Jurnal Penelitian dan Pengembangan Pendidikan Fisika), vol. 2, no. 1, pp. 57 - 64, 2016.

[7] M. G. Nugraha, K. H. Kirana, S. Utari, N. Kurniasih, N. Nurdini, and F. N. Sholihat, "Problem Solving-Based Experiment untuk Meningkatkan Keterampilan Penalaran Ilmiah Mahasiswa Fisika", JPPPF (Jurnal Penelitian dan Pengembangan Pendidikan Fisika), vol. 3, no. 2, pp. 137 - 144, 2017.

[8] A. Malik, E. Kurnia Y, and S. Robiatus S, "Peningkatan Keterampilan Proses Sains Siswa melalui Context Based Learning", JPPPF (Jurnal Penelitian dan Pengembangan Pendidikan Fisika), vol. 2, no. 1, pp. 23 - 30, 2016.

[9] R. Haryadi and H. Pujiastuti, "Discovery Learning based on Natural Phenomena to Improve Students' Science Process Skills", JPPPF (Jurnal Penelitian dan Pengembangan Pendidikan Fisika), vol. 5, no. 2, pp. 183 - 192, 2019.

[10] R. Athiyyah, T. Al Farizi, and D. Nanto, "Improvement of Science Process Skills Through Sound Variable Intensity Level Tool Kit", JPPPF (Jurnal Penelitian dan Pengembangan $\begin{array}{lllllllll}\text { Pendidikan Fisika), } & \text { vol. } \quad 6, & \text { no. } & 1, & \text { pp. } & 89 & - & 96,\end{array}$ 
